\title{
Ultrasound-Guided Axillary Block in an Anticoagulated Patient after Heartmate II Implantation
}

\author{
Giuseppe Trunfio, Boris Yaguda, Paul C. Saunders, Dennis E. Feierman \\ Departments of Anesthesiology and Surgery, Maimonides Medical Center, Brooklyn, USA \\ Email: dfeierman@maimonidesmed.org
}

Received 23 May 2014; revised 28 June 2014; accepted 11 July 2014

Copyright (C) 2014 by authors and Scientific Research Publishing Inc.

This work is licensed under the Creative Commons Attribution International License (CC BY).

http://creativecommons.org/licenses/by/4.0/

\section{(c) (i) Open Access}

\begin{abstract}
Objective: This case exemplifies the understanding of the physiological changes associate with 1) Left Ventricular Assist Devices, 2) monitoring challenges associated with Left Ventricular Assist Devices and 3) the usefulness of peripheral nerve blocks in this subset of patients. Case report: $A$ 73-year-old man was scheduled for left wrist arthroscopy and debridement to treat a very painful septic joint. He had undergone Heartmate II Left Ventricular Assist Device implantation uneventfully for Destination Therapy 4 months prior. The patient required maintenance of therapeutic anticoagulation. We elected for an ultrasound-guided axillary block, which limits the risks of vascular injury in presence of high INR. The axillary nerve block enabled us to overcome potential anesthetic problems in a patient with a continuous flow LVAD. Conclusion: The physiologic principles of Left Ventricular Assist Device function should be understood before the initiation of anesthesia. Regional Anesthesiologists can offer a very significant contribution to the safe care of patients with heart failure requiring a continuous flow Left Ventricular Assist Device.
\end{abstract}

\section{Keywords}

Ultrasound-Guided Block, Anticoagulation LVAD

\section{Introduction}

Treatment modalities for left ventricular failure are limited. Despite advances in pharmacological treatment, 1 year survival with maximal medical therapy for stage IV NYHA Congestive Heart Failure remains poor. Heart transplantation is an effective treatment, but is limited by the availability of donor hearts. The REMATCH trial showed a marked improvement in survival with surgically implanted Left Ventricular Assist Devices (LVAD) 
[1]. The decline in complications and increased survival associated with Heartmate II implantation has dramatically increased the number of patients offered this device, now over 15,000 world-wide [2]. The device is essentially a small, battery-operated non-pulsatile axial flow pump that circulates blood from the apex of the left ventricle to the ascending aorta. No support is provided to the right ventricle and a moderate degree of chronic anticoagulation is required. These patients can lead an active lifestyle and do not necessarily refer for their care to the center that implanted the device [3]. They often necessitate non-cardiac procedures presenting unusual problems for anesthetic management [4]. In spite of the issues with anticoagulation, regional blocks offer distinctive advantages for the anesthetic care of these patients.

\section{Case Presentation}

A 73-year-old man was scheduled for left wrist arthroscopy and debridement to treat a very painful septic joint. He had undergone Heartmate II implantation uneventfully for Destination Therapy for heart failure 4 months prior. Coumadin treatment resulted in a 2.4 INR. A $20 \mathrm{~g}$ right antecubital peripheral access was present. The patient's height and weight were 67”, 92 kg, respectively. In the Operating Room heart rhythm was noted to be sinus with a rate of 89. Pulse oximetry was reading intermittently, systemic blood pressure measured by Terumo Elemano flow meter was 113/95. The Terumo Elemano blood pressure monitor is a novel slow-cuff deflation system, which enhances sensitivity and detection of blood pressure in patients with reduced arterial pulse pressure [5].

A left axillary block was performed under ultrasound guidance after the intravenous administration of 50 micrograms of Fentanyl. A total of 15 milliliters of Lidocaine $1.5 \%$ and 15 milliliters of Ropivicaine $0.5 \%$ were administered for the block, evenly distributed among the brachial plexus nerves. The arm appeared insensate not long after the completion of the block, but the patient was very anxious and strongly desired to be "totally out" for the procedure. General anesthesia was then induced with $20 \mathrm{mg}$ of etomidate and \#4 Laryngeal Mask Airway (LMA) placed. Since the ICU staff required central venous access for antibiotic treatment, a right internal jugular central line under ultrasound guidance was performed. General Anesthesia was maintained with inspired isofluorane at $0.5 \%-0.6 \%$ with spontaneous ventilation. Oxygenation on $\mathrm{FIO}_{2}=1$ during the case was always above $98 \%$ and end tidal $\mathrm{CO}_{2}$ was $29-30 \mathrm{~mm} \mathrm{Hg}$. Blood loss was minimal and fluid intake was approximately $250 \mathrm{ml}$ of Ringer's Lactate. The case was uneventful with a pain-free, satisfied patient at the end of the procedure.

\section{Discussion}

The Heartmate II is an implantable, axial-flow Left Ventricular Assist Device capable of providing a cardiac output up to $10 \mathrm{l} / \mathrm{min}$. Blood is directed from a cannula in the left ventricular apex to an impeller and then to the ascending aorta (Figure 1). The flow of the device is non-pulsatile and is typically adjusted to allow the aortic valve open intermittently [6]. Since pulse oximetry and oscillometric blood pressure monitors have limited utility with non-pulsatile flow, monitoring has to rely more on invasive blood pressure monitoring and cerebral oximetry [7] [8]. Right Ventricular function is required to fill the Left Ventricle. Factors that decrease preload (such as positive pressure ventilation) or increase pulmonary vascular resistance (PVR) and reduce right ventricular output (e.g. hypoxia, hypercarbia, and acidosis) can reduce inflow and cause low pump output and severe hypotension [9]. The device is also afterload-sensitive and a sudden increase in systemic vascular resistence (SVR), for example due to light anesthesia, will cause a marked decrease in forward flow. In order to better control these factors, general endotracheal anesthesia (GETA) with mechanical ventilation usually require invasive monitoring [10]. This however entails the administration of significant amount of anesthetics with the possibility of undesirable hemodynamic fluctuations and prolonged postoperative intubation. In our patient we elected for an ultrasound-guided axillary which limits the risks of vascular injury in presence of high INR. Even if an axillary block requires more needle passes than a supra or an infraclavicular block, increasing the possibility of a hematoma, the area is compressible and there is no risk of pneumo or hemothorax. Since the patient adamantly desired not to be conscious for the procedure, we opted for a general inhalational anesthetic with the patient spontaneously breathing through a laryngeal mask. We deemed that a deep sedation technique without airway control, for example, with a continuous infusion of a hypnotic agent, may have entailed an increased risk of hypercarbia and increase in PVR. Although this technique could potentially expose the patient to the risk of hypercarbia and increased pulmonary vascular resistance, we found that with the arm rendered insensate arm by 


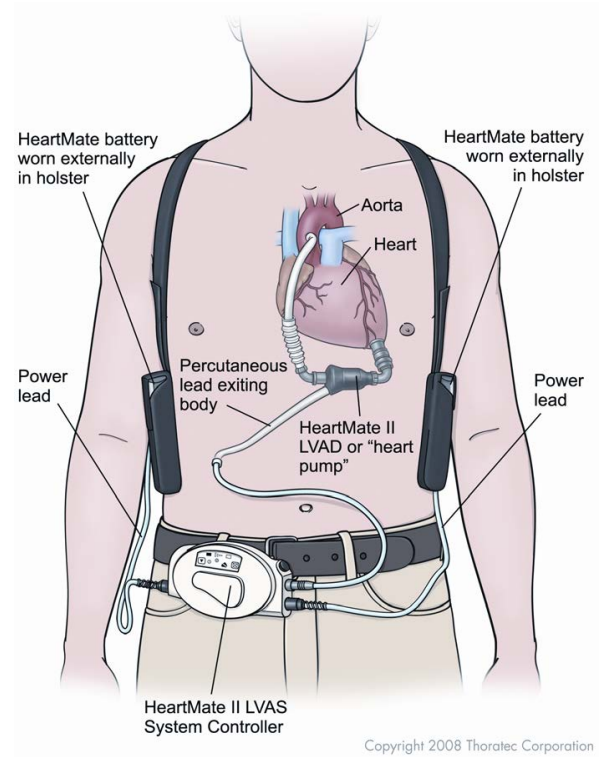

Figure 1. Heartmate II: inflow cannula from the apex of the Left Ventricle, Pump, outflow cannula to the Ascending Aorta, Driveline, System controller and External Battery Packs. Reprinted with the permission of Thoratec Corporation.

the peripheral nerve block the required level of inhalation anesthetic was minimal, and the increase of end-tidal $\mathrm{CO}_{2}$ contained. Some authors suggest considering these patients "full stomach" because of the properitoneal location of the device [9]. After consulting with the surgeon regarding the exact location of the device in this patient, we deemed that the risk of a "full stomach" was limited. Furthermore, spontaneous ventilation depresses venous return less than GETA with mechanical ventilation. Intubation with an LMA results in a limited increase in SVR compared to endotracheal intubation and allows for prompt extubation at the end of the procedure. GETA with mechanical ventilation would require more airway manipulation and potentially less manageable hemodynamic variations (especially the combination of decreased venous return with SVR fluctuations) and potentially a longer recovery period.

The anesthetic management of Heartmate II patients has to be carefully planned even for simple surgical procedures. Regional Anesthesiologists can offer a very significant contribution to the safe care of these patients, once the physiologic principles of LVAD functioning are understood. All LVAD flow is critically dependent on right ventricular function, so avoidance of increases of PVR is paramount. If surgical stimulation is removed with a peripheral nerve block, light sedation is ideal. If this is not possible, a light general anesthetic via an LMA is preferable to deep intravenous sedation. GETA can also be used but necessitates deeper level of anesthesia, possibly more invasive monitoring, and a longer recovery period.

\section{References}

[1] Rose, E.A., Gelijns, A.C., Moskowitz, A.J., Heitjan, D.F., Stevenson, L.W., Dembitsky, W., Long, J.W., Ascheim, D.D., Tierney, A.R., Levitan, R.G., Watson, J.T., Meier, P., Ronan, N.S., Shapiro, P.A., Lazar, R.M., Miller, L.W., Gupta, L., Frazier, O.H., Desvigne-Nickens, P., Oz, M.C., Poirier, V.L. and Randomized Evaluation of Mechanical Assistance for the Treatment of Congestive Heart Failure Study G (2001) Long-Term Use of a Left Ventricular Assist Device for End-Stage Heart Failure. The New England Journal of Medicine, 345, 1435-1443. http://dx.doi.org/10.1056/NEJMoa012175

[2] Kirklin, J.K., Naftel, D.C., Kormos, R.L., Stevenson, L.W., Pagani, F.D., Miller, M.A., Timothy Baldwin, J. and Young, J.B. (2013) Fifth INTERMACS Annual Report: Risk Factor Analysis from More than 6,000 Mechanical Circulatory Support Patients. The Journal of Heart and Lung Transplantation, 32, 141-156. http://dx.doi.org/10.1016/j.healun.2012.12.004

[3] Rogers, J.G., Aaronson, K.D., Boyle, A.J., Russell, S.D., Milano, C.A., Pagani, F.D., Edwards, B.S., Park, S., John, R., 
Conte, J.V., Farrar, D.J., Slaughter, M.S. and HeartMate II Investigators (2010) Continuous Flow Left Ventricular Assist Device Improves Functional Capacity and Quality of Life of Advanced Heart Failure Patients. Journal of the American College of Cardiology, 55, 1826-1834. http://dx.doi.org/10.1016/j.jacc.2009.12.052

[4] Slininger, K.A., Haddadin, A.S. and Mangi, A.A. (2013) Perioperative Management of Patients with Left Ventricular Assist Devices Undergoing Noncardiac Surgery. Journal of Cardiothoracic and Vascular Anesthesia, 27, 752-759. http://dx.doi.org/10.1053/j.jvca.2012.09.022

[5] Lanier, G.M., Orlanes, K., Hayashi, Y., Murphy, J., Flannery, M., Te-Frey, R., Uriel, N., Yuzefpolskaya, M., Mancini, D.M., Naka, Y., Takayama, H., Jorde, U.P., Demmer, R.T. and Colombo, P.C. (2013) Validity and Reliability of a Novel Slow Cuff-Deflation System for Noninvasive Blood Pressure Monitoring in Patients with Continuous-Flow Left Ventricular Assist Device. Circulation: Heart Failure, 6, 1005-1012. http://dx.doi.org/10.1161/CIRCHEARTFAILURE.112.000186

[6] Sheikh, F.H. and Russell, S.D. (2011) HeartMate ${ }^{\circledR}$ II Continuous-Flow Left Ventricular Assist System. Expert Review of Medical Devices, 8, 11-21. http://dx.doi.org/10.1586/erd.10.77

[7] Argiriadou, H., Anastasiadis, K., Antonitsis, P., Karapanagiotidis, G., Foroulis, C.N., Piggott, D., Papakonstantinou, C. and Westaby, S. (2010) Use of Cerebral Oximetry for Monitoring Cardiac Output during Off-Pump Implantation of Jarvik 2000 Left Ventricular Assist Device. Artificial Organs, 34, 267-271. http://dx.doi.org/10.1111/j.1525-1594.2009.00827.x

[8] Oleyar, M., Stone, M. and Neustein, S.M. (2010) Perioperative Management of a Patient with a Nonpulsatile Left Ventricular-Assist Device Presenting for Noncardiac Surgery. Journal of Cardiothoracic and Vascular Anesthesia, 24, 820-823. http://dx.doi.org/10.1053/j.jvca.2009.06.004

[9] Ficke, D.J., Lee, J., Chaney, M.A., Bas, H., Vidal-Melo, M.F. and Stone, M.E. (2010) Case 6-2010: Noncardiac Surgery in Patients with a Left Ventricular Assist Device. Journal of Cardiothoracic and Vascular Anesthesia, 24, $1002-$ 1009. http://dx.doi.org/10.1053/j.jvca.2010.09.005

[10] Barbara, D.W., Wetzel, D.R., Pulido, J.N., Pershing, B.S., Park, S.J., Stulak, J.M., Zietlow, S.P., Morris, D.S., Boilson, B.A. and Mauermann, W.J. (2013) The Perioperative Management of Patients with Left Ventricular Assist Devices Undergoing Noncardiac Surgery. Mayo Clinic Proceedings, 88, 674-682.

http://dx.doi.org/10.1016/j.mayocp.2013.03.019 
Scientific Research Publishing (SCIRP) is one of the largest Open Access journal publishers. It is currently publishing more than 200 open access, online, peer-reviewed journals covering a wide range of academic disciplines. SCIRP serves the worldwide academic communities and contributes to the progress and application of science with its publication.

Other selected journals from SCIRP are listed as below. Submit your manuscript to us via either submit@scirp.org or Online Submission Portal.
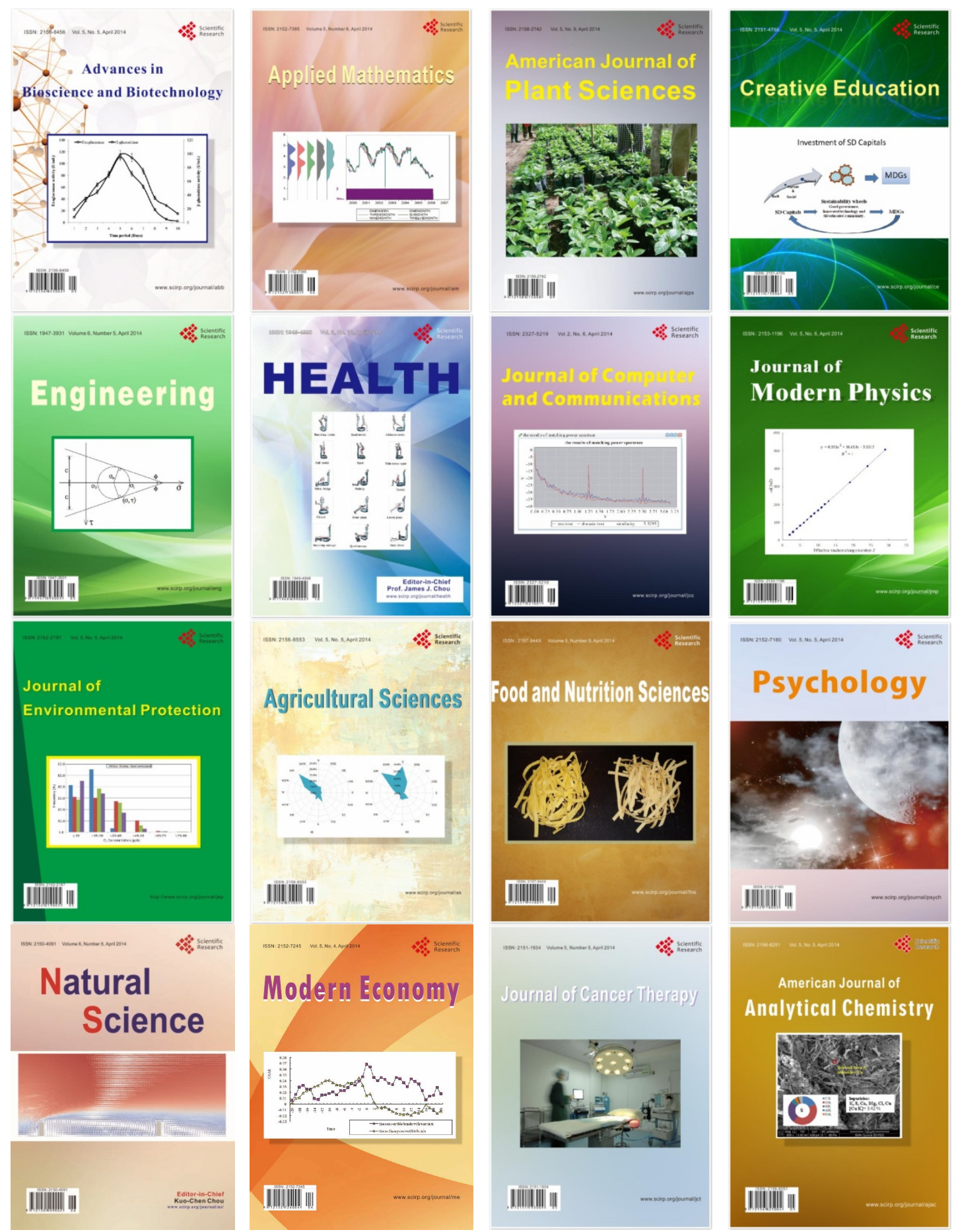